\title{
The Application of Digital Media arts in the Public Service Advertisements ( PSAs)
}

\author{
Zhu Ming \\ Lecturer of Art College, Dalian Jiaotong University
}

\begin{abstract}
Digital Media Arts is the combination of technology and the arts has a very broad application. In modern society, PSAs is also a combination of technology and the arts. As the development of digital media arts, the forms of spread, expression language, methods of making etc. of PSAs have changed quickly. Through the analysis of forms, types, development of PSAs and the current digital media, the applications of digital media arts in the PSAs are discussed on the use of social public in this paper.
\end{abstract}

Keywords: Digital media arts, Society public service ads, Holographic interactive technology, Spread function

\section{Digital media arts and the analysis of social PSAs}

\subsection{The overview of digital media arts}

Digital media art is a new art form that blends person's rational thinking and emotional thinking of art based on digital technology and modern media technology. In 19th century, the emergence of photography, television and other media carrier marks the era of media. In the 1970s, along with the computer system was born in Bell Labs, the establishment of Internet language and the development and occurs of Web browser GUI in the 1990s, the transmission forms of information take a gradually transition from the mass media to digital media, then digital media arts rises in response to the proper time and conditions. His generation based on science technology, meanwhile, digital media is constantly changing with the continuous development of science and technology. From the "inside" of technological innovation and the concept of change, to the "outside" of the type and form of a blend and interactivity etc, with other industries, with the times. There are various manifestations of digital media, such as: digital radio and television media, multimedia CD-ROM, digital imaging, portable digital entertainment devices, networks arts etc.

\subsection{The development and co- prosperity of social PSAs and digital media arts}

Social PSAs originated in the economic crisis of the United States in the 1940s. November 1941, James Webber Yang known as the Ad Council founder pointed out in the famous thirty minutes speech that "advertising should allow people to promote mutual understanding, to resolve their differences in public advocacy tools, ads should meet national needs and do more good, and also, should disseminate music, literature, art, justice forces and play a higher realm. " Social PSAs is able to come today, these words are still its essence.

Social PSAs is a kind of communications technology which based on information science and digital technology, take television, Internet and other media as a medium, for the purpose of infor- 
mation dissemination. And is also a product when social material culture and spiritual culture reaches a certain level. It is different from commercial advertising, for the function of dissemination of positive thinking, enhance the overall quality of society, and serve the society. With the increase of people's aesthetic requirements, art forms constantly diversified, PSAs express emotion more through creative, artistic skills instead of traditional single didactic model, which arouses sympathy. PSAs starts late in our country, it's nearly thirty years from the first case of "water saving" in 1986 comes to today, but in the three decades, the forms of communication, manifestation mode, production methods etc. produced tremendous change with the development of digital media art.

\section{The application of digital media art in social PSAs}

Good social at the same time should be close to the people's livelihood and is associated with people's life and social development. If you want to spread a social PSAs, you need to drive the people's thought, or change people's behavior, the most important thing is to attract people's attention and make people willing to finish seeing the advertising then will have the possibility of continue thinking. So what can attract the audiences? Traffic laws in the United States have "three second principle", the British psychology biologist Colwyn Trevarthen at the University of Edinburgh, also founded that 3 seconds mode is very important to the basis of our conscious experiences. When people take down the remote choosing channel depends largely on the gaze of 3 seconds. That is to say, in today's social and cultural entertainment, social PSAs and movies, TV shows, games and drama are in front of audiences at the same time, to seize the audience instantly, the de- mand for social PSAs will be higher. The ideas will be more innovative the making will be more excellent, the pictures will looked better, the sound will be more attractive. To achieve these, we need apply more digital media art in the social PSAs.

\subsection{To nonlinear narrative for the mainstream Use more flexiblenarrative}

Narrative divided into two categories: linear and nonlinear. Nonlinear narrative has broken the traditional linear narrative in the order of story taking place, is an editing method used in the latter of editing the file or video media, come true through the software and hardware of the nonlinear editing system. "Packaging", an piece of PSAs caring dementia old man, broadcasted by CCTV at the beginning of 2013, called on people to care for the old man by telling the theme of "father had forgotten everything, but never forget to love for the son" in the way of nonlinear narrative plug-in montage technique of expression. This ad mainly affect people by love and makes people resonate. The use of this non-linear narrative technique also plays an important role in the accumulation of emotions. "Dumb ways to die an piece of public service ads made by Australia to promote the production of railway safety, also used the way of nonlinear storyline narrative in the storyline, unfolded vividly about 21 kinds of stupid "die" by repeat montage technique of expression, In the irony warned people not losing lives because of carelessness.

\subsection{Enrich the forms of Society PSAs}

The society PSAs have presented more expressions with the update of the digital media technology, hardware and software: The 2D animation, 3D animation, synthetic production by the form shooting combined with computer processing, virtual reality and so on, in the form of $2 \mathrm{D}$ animation, the traditional 2D animation 
method because of the heavy workload is gradually replaced by digital technology, for example, by digital technology rendering to complete 2D ink animation, the advertising of "Believing in the power of the brand" in CCTV is completed by 3D software combined with later software rendering works. The flash software which is applied to flash animation of $2 \mathrm{D}$ animation because of the simple manufacturing process and excellent effect is also widely used. Public service ads film show by the digital media technology or has a strong national culture color, or teaching through lively activities, or dignified form of rich of great momentum.

2.3. To realize the "true aesthetics" of social PSAs through the artistic language such as composition, light, color, lens using etc.

The composition, lighting, color, etc. In the picture is an important part of social PSAs, directly impact on the audience psychology, plays an important role in the spread function. In color, for example, colorific hue, lightness, purity, complementary color, contrast of changes in temperature, all have the effect to the expression of emotions and atmosphere. And the color psychology of different color is also different, for example, the brilliant color gives a person light and colorful feeling, the low lightness gives a person the sense of dense and depression, the cool color gives a person the sense of cold and rational, and the warm color gives a person warm and sweet feeling. The rhythm of the picture, the density of line, color, light and shadow processing in a different way will bring a different feeling to the audience. A good PSAs will guide the audience's behavior, and the first is to let the audience believe the truth of it, thus will reach the good effect. So good screen lens language would resonate with people, and achieve the purpose of publicity and education. And these, can be offered by digital media art.

\subsection{Digital media art plays interactive function in the process of communica- tion}

Public service ads cann't only spread, but also interact with the audience. The Australia PSAs "Dumb ways to die" is the typical example of this aspect. This advertising is played like a game, the player need to save the role of cute version in the game, and avoid them to die. The whole advertising have slightly bloody color, the style is relaxed, ridiculous, the music is fresh and catchy, in the process of singing and game realized the interactive function between the "Dumb ways to die" and the audiences or game players, and the propaganda effect of advertisement can be realized.

\section{Applications of Digital Media Arts in the PSAs will have a broader out- look}

\subsection{Forms of digital carrier in PSAs becomes more diverse}

The current digital media arts and interactive design is the future development trend, and the carrier of social PSAs should also be enriched with digital morphological evolution. From using television as the main media today to the LED digital display in the city, with the completion of the digital city, digital virtual cities such as digital Beijing, digital Macau, social public service ads can also use virtual model as its existing carrier.

3.2. Along with the advent of the holographic times, big changes will occur in interactive features of the digital media advertisement art

Art forms change from simplification to diversification, then to the "era of digi- 
tal network interaction" from diversification.Images, voice, text, graphics etc., fuse in a new way, from the "finished" art to "process" is art, from the static 2D plane to three-dimensional space of virtual reality, from real to virtual stream of consciousness in the brain, and so on. With the birth of the holographic technology, audiences don't have to face the screen to feel the works, they can go into the works as if being personally on the scene.

In Jay's concert in Taipei in 2013, using holographic technology virtual image reconstruction of Teresa Teng, bring to the audiences the feeling that find everything new and fresh, the reproduction technology will make virtual things performance very solid and real. In 2009, the exhibition of the world classic art multimedia interactive was exhibited in Beijing, the exhibition works including many influential works of art, such as the Mona Lisa, the last supper, when people intoxicated in one of these classic works, they forgot that the virtual work were created only with holographic technology. Maybe one day, when we walk near the faucet turning a blind eye to wasting water, probably around us public service ads will be in a new way using holographic imaging system to present the images of the earth resources exhaustion because of wanton wasting resources, and make that as if we place ourselves among the scene.

\section{Conclusions}

The fusion of digital media art and social PSAs is a kind of artistic idea using technology to convey the social welfare, this thought is the common social responsibility of artists and scientists. No matter in three dimensions technology or holographic technology, what they final expressed is the art ray that saturated with internal social responsibility.

\section{References}

[1] Reference the American advertising board web site http://www.adcouncil.org/timeline.ht $\mathrm{ml} /$, loaded in February 14, 2009.

[2] Chen H.B., Talking about when advertising committee and the birth of the American public service ads in war [J]. Daguan Ads.2009,02. (In Chinese)

[3] Chen Z.Y., Digital media arts impact on animation design[J]. Youth. 2011, 06. (In Chinese)

[4] Zhai F.J., A brief analysis of the interaction design development in new media art[J]. Intelligence. 2012,09. (In Chinese)

[5] Qin N., Analysis of Holography and digital media arts integration $[\mathrm{J}]$. Contemporary Visual Art Research.2010,01. (In Chinese)

[6] Wang X., the impact of digital media arts on animation design[J]. Splendid chapter. 2011,04. (In Chinese)

[7] $\mathrm{Wu}$ Q. and Li F.C., Social Effects of the PSAs. Advertising and marketing. 2009,01. (In Chinese)

This paper is about a project "The application research of digital media technology in the field of animation in the new media era" research component of Liaoning Provincial Department of Education. Project approval number: W2012065 